\title{
Mechanical behavior after repairing structure by fiber carbon
}

\section{Comportamiento mecánico de una estructura después de la reparación por fibras de carbono}

Tayeb Ayad (Main Author)

Laboratoire Méthode et Procédé de Construction, Département d’Architecture et Génie Civil

Université de Mostaganem Algérie (Algérie)

tayeb.ayad@univ-mosta.dz

Tahar Kadri (Corresponding Author)

Directeur du Laboratoire Méthode et Procédé de Construction, Département d'Architecture et Génie Civil

Université de Mostaganem Algérie (Algérie)

tahar.kadri@univ-mosta.dz

\section{Ahmed Rezigua}

Laboratoire Méthode et Procédé de Construction, Département d'Architecture et Génie Civil

Université de Mostaganem Algérie (Algérie)

ahmed.rezigua@univ-mosta.dz

\author{
Manuscript Code: 769 \\ Date of Acceptance/Reception: 08.11.2017/04.05.2016 \\ DOI: 10.7764/RDLC.16.3.412
}

\begin{abstract}
In this paper, an analytic study is presented to investigate the effect of crack length on the single-lap shear joint under tensile load and to analyze the distribution of adhesive shear stress. A parametric study was conducted in accordance with changes in dimensions of the pre-crack position to evaluate shear stress along the bonded joint. A finite element analysis (FEA) was proposed for validation of our analytic model and for determination of stress concentration points of the pre-crack and the two edges of the bonded assembly. Results in this paper show good agreement between analytic study and the FEA model for shear stress at both free edges of adhesive.
\end{abstract}

Keywords: composite, shear stress, bonded assembly, crack, structure.

\section{Resumen}

En este trabajo, se presenta un estudio analítico para investigar el efecto de la longitud de la fisura en la junta de cizalla de sola vuelta bajo carga de tracción y para analizar la distribución del esfuerzo cortante adhesivo. El estudio paramétrico se realizó de acuerdo con los cambios en las dimensiones de la posición de pre-grieta, para evaluar la tensión de cizallamiento a lo largo de la junta pegada. Se propuso un análisis de elementos finitos (FEA), para la validación de nuestro modelo analítico y para la determinación de puntos de concentración de esfuerzos de la pre-grieta y los dos bordes del conjunto unido. Los resultados en este documento muestran una buena concordancia entre el estudio analítico y el modelo de FEA para el esfuerzo cortante, en ambos bordes libres del adhesivo.

Palabras clave: compuesto, tensión de cizallamiento, ensamble pegado, grieta, estructura.

\section{Introduction and Description of the Problem}

Adhesive bonding features many advantages over traditional techniques, such as riveting or welding. First, adhesive bonding is rapidly implemented, especially because of its automated application. This technique allows fitting of different fragile or thin materials. Blending between materials continuously occurs to avoid stress concentrations. Adhesive bonding produces higher mechanical strength than that produced by riveting. Furthermore, adhesive bonding does not require significant local heating; thus, compared with welding, this method does not alter the properties of materials to be assembled. Weight gain is important for structure by replacing bolts; rivets with a few linear meters of glue. Adhesives absorb some vibration and provide both acoustic and electric thermal insulation. However, bonding technique for assembling complex surface preparation must be meticulous. Many models for adhesive bonded joints were developed using single-lap joint geometries. This configuration has been adopted by (ASTM) the American Society of Testing Materials as standard mechanical test for the determination of distribution shear stress. Goland \& Reissner (1944) were the first to include the effects of eccentric load path by applying moments at the edges of the joint. Erdogan \& Ratwan(1971) single-lap joint configurations have been studied for about 60years, and numerous analytic and numerical models have been developed. Hart-Smith(1973) provided a considerable amount of work on glued joints that are in single layer, double overlapped, stepped, and chamfered. Analytic solutions have incorporated thermal effects and the effects of imbalance rigidity. In addition,Hart-Smith(1985) became interested in non-linear behavior of adhesives and developed an approach to perfect elastic-plastic bonding. Hutchinson \& Suo(1991) believed that most of 
the important fracture concepts for layered systems emerge in the analysis of steady-state cracking also Kairouz \& Matthews (1993) investigated on Strength and failure modes of bonded single lap joints between cross-ply adherends. This method of analysis has been developed to investigate the size of crack in adherents near overlap ends and their effect on failure behavior of adhesive single lap joint byTong(1998).

Numerical methods can be used to analyze models with arbitrary geometries and load conditions. The two-dimensional finite element analysis (FEA) of adhesive-bonded joints were adopted by many researchers, such as Rybicki \& Kanninen(1977) calculation of stress intensity factors by a modified crack closure integral by Adams(1989) for Classical linear solutions of the lap joint problem discussed with more advanced versions; alsoLiyong Tong \& Steven(1999). The problem of this study is the existence of crack length that significantly redistributes stresses in the adhesive layer and thus changes stress resultants in both adherends. The main objective of this paper is to study the effect of crack length on stress distributions in adhesive layer by introducing a corrector factor with the combination of (Goland \& Reissner, 1944) approach and (Cheuk \& Tong, 2002) analysis.

Preparation of this manuscript aimed to achieve the following:

- Simplification of the model and the governing differential equations

- Results of deflection and bending moment for a single-overlap joint loaded with a tensile force

- This work aimed to study the effect of crack length on shear stress distributions in adhesive layers.

\section{Nomenclature}

$M_{1}: \quad$ Bending moment at position $\mathrm{x}_{1}(\mathrm{~N} . \mathrm{mm} / \mathrm{mm})$;

$P: \quad$ Applied load $(\mathrm{N} / \mathrm{mm})$;

$W_{1}$ : $\quad$ Deflection at position $\mathrm{x}_{1}(\mathrm{~mm})$;

$R_{A}: \quad$ Reaction at crack point A $(\mathrm{N} / \mathrm{mm})$;

$M_{A}: \quad$ Bending moment at crack point A (N.mm/mm);

Mo: $\quad$ Bending moment at xo position (N.mm/mm);

$\alpha_{n}: \quad$ Eccentricity ratio (\%);

$I_{A}: \quad$ Overlap length of single lap shear joint $(\mathrm{mm})$;

$I_{B}: \quad$ Free lap length of single lap shear joint $(\mathrm{mm})$;

$w_{0}$ : Deflection of single lap shear joint at position $\mathrm{x}_{0}(\mathrm{~mm})$;

$h_{1}$ : $\quad$ Upper adherend thickness (strap) (mm);

$h_{2}$ : Lower adherend thickness (lap) (mm);

$t_{1}$ : $\quad$ Adhesive thickness $(\mathrm{mm})$;

$c$ : Overlap length of single lap shear joint $(\mathrm{mm})$;

$\Delta: \quad$ Undimensional quantity (\%);

$\eta$ : $\quad$ Thickness ratio of $h_{1}, h_{2}(\%)$;

$\Sigma$ : $\quad$ Young modulus ration of adherends (\%);

$\hat{R}_{A}$ : Undimensional reaction force (\%);

$\widehat{M}_{A}$ : Undimensional bending moment (\%);

$Q_{1}$ : $\quad$ Shear force at position $\mathrm{x}_{1}(\mathrm{~N} . \mathrm{mm} / \mathrm{mm})$;

$Q_{2}: \quad$ Shear force at position $\mathrm{x}_{2}(\mathrm{~N} . \mathrm{mm} / \mathrm{mm})$;

$D_{1}$ : $\quad$ Adherend bending stiffness (N.mm);

$D_{2}$ : $\quad$ Adherend bending stiffness (N.mm);

$E_{1}$ : $\quad$ Young modulus of adherend $(\mathrm{MPa})$;

v: $\quad$ Poisson ratio (\%);

$u_{1}$ : Displacement at crack point $\mathrm{x}_{1}(\mathrm{~mm})$;

$u_{2}$ : Displacement at crack point $\mathrm{x}_{2}(\mathrm{~mm})$;

$X_{A}: \quad$ Half crack length at section $A(\mathrm{~mm})$;

$X_{B}: \quad$ Half crack length at section $B(\mathrm{~mm})$;

k: $\quad$ Corrector factor for bending moment

$\tau_{x y}: \quad$ Adhesive shear stress (MPa); 
An analytic model was proposed to calculate forces and moments, resulting in different sections of the specimen, including the cracked zone and interface. The solution procedure involves comprehensive analysis of the joint. Figure 1 shows the joint with an imposed crack in the adherend. A concentrated load $P$ is applied to the center line of each edge. Crack length $\mathrm{c}$ is imposed on the surface of adhesive at distance $t_{1}$. Thickness of the substrate equals $h$, whereas thickness of adhesive is $\eta$. Two coordinate systems are involved: the first is located at the free edge $\left[x_{0}, z\left(w_{0}\right)\right]$, and the other is located in the middle of the adhesive layer $\left[x_{1}, z\left(w_{1}\right)\right]$. The crack is bounded on both left and right sides by two sections $A$ and $B$, respectively. The crack presents a crack tip at section $A$ inside the overlap and a crack tip at section $B$ outside the joint. As shown in Figure1, the crack features a length of $x_{A}+x_{B}$, where $x_{A}$ is the length of the crack part inside the overlap, and $x_{B}$ refers to the length of the crack part outside the overlap.

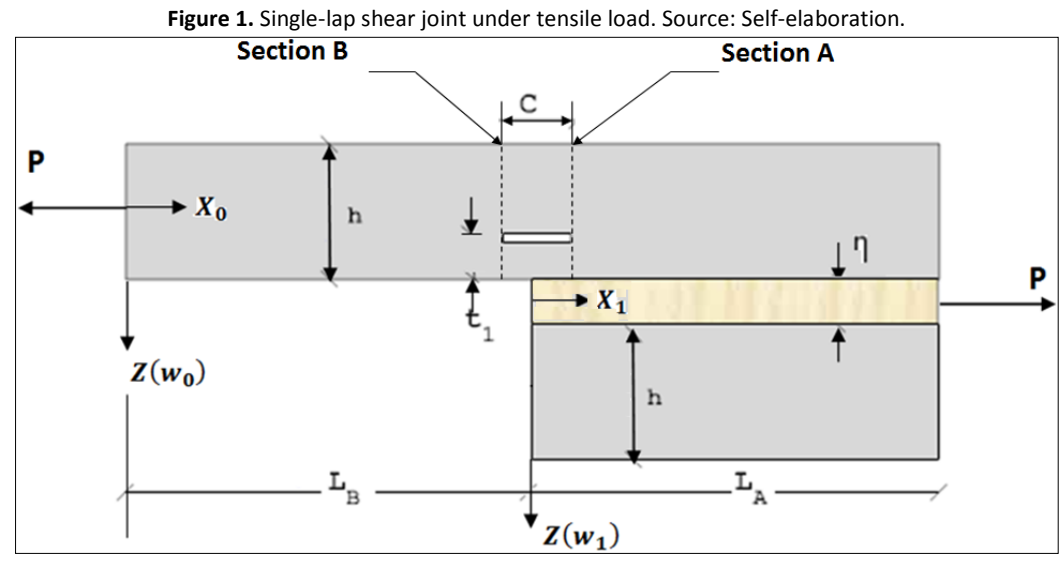

for $\quad 0 \leq x_{1} \leq l_{A}$

$M_{1}=P\left(\alpha_{n} x_{1}-w_{1}+\frac{R_{A}}{P} x_{1}+\frac{M_{A}}{P}\right)$

for $\quad 0 \leq x_{0} \leq l_{B}$

$M_{0}=P\left[\alpha_{n}\left(x_{0}+l_{A}\right)-w_{0}-\left(\frac{h_{1}}{2}+h_{2}-\Delta h_{1}\right)+\frac{R_{A}}{P}\left(x_{0}+l_{A}\right)+\frac{M_{A}}{P}\right]$

Similar to the thin plate's cylindrical bending theory, the differential equations for the cross section, $w_{1}$ and $w_{0}$ are given by the following:

$\frac{d^{2} w_{1}}{d x_{1}^{2}}=-\frac{M_{1}}{D_{1}}=-\frac{P}{D_{1}}\left(\alpha_{n} x_{1}-w_{1}+\frac{R_{A}}{P} x_{1}+\frac{M_{A}}{P}\right)$

And

$\frac{d^{2} w_{0}}{d x_{0}^{2}}=-\frac{M_{0}}{D_{0}}=-\frac{P}{D_{0}}\left[\alpha_{n}\left(x_{0+l_{A}}\right)-w_{0}-\left(\frac{h_{1}}{2}+h_{2}-\Delta h_{1}\right)+\frac{R_{A}}{P}\left(x_{0}+l_{A}\right)+\frac{M_{A}}{P}\right]$

$D_{0}=\frac{Q_{11} h^{3}}{12} ; D_{1}=\frac{2 Q_{11} h^{3}}{3} ; Q_{11}=\frac{E_{1}}{1-v_{12} v_{21}} ; \quad \widehat{M}_{A}=\frac{M_{A}}{P L}$ and $\hat{R}_{A}=\frac{R_{A}}{P}$

$D_{0}$ and $D_{1}$ are adherent bending stiffness.

Solving differential Equations (3) and (4), we obtain the following:

$\frac{w_{1}}{L}=A_{1} \cosh \left(\lambda_{1} x_{1}\right)+B_{1} \sinh \left(\lambda_{1} x_{1}\right)+\left(\alpha_{n}+\hat{R}_{A}\right) \frac{x_{1}}{L}+\widehat{M}_{A}$

$\frac{w_{0}}{L}=A_{0} \cosh \left(\lambda_{0} x_{0}\right)+B_{0} \sinh \left(\lambda_{0} x_{0}\right)+\left[\left(\alpha_{n}+\hat{R}_{A}\right) \frac{\left(x_{0}+l_{A}\right)}{L}-\alpha_{n}+\widehat{M}_{A}\right]$ 
Global bending moments $M_{A}$ and $M_{B}$ are obtained as follows:

At crack tip A, $x_{1}=x_{A}$

$M_{A}=\frac{P \cdot t \cdot \cosh \left(\lambda_{1} \cdot x_{A}\right)}{2} \cdot\left(-1+k\left(1+\frac{\left(\mu_{1} \cdot \tanh \left(\lambda_{1} \cdot x_{A}\right)\right)}{\left(\mu_{2} \cdot \tanh \left(\lambda_{0} \cdot l\right)\right)}\right)\right)$

At crack tip B, $x_{0}=x_{B}$

$M_{B}=\frac{k \cdot P \cdot t \cdot \sinh \lambda_{0}\left(l-x_{B}\right)}{2 \cdot \sinh \left(\lambda_{0} \cdot l\right)}$

\section{Bending moment factor according Goland and Reissner}

In this case, bending moment and shear force are non-collinear. When the imposed load $P$ is weak, rotation in the overlap region becomes negligible; bending moment at the edge is expressed by the following:

$M_{0}=\frac{P t}{2}$

When the load is increased, rotation in the overlap region becomes important. This rotation is transmitted to the edges of the bonded assembly. Considering this case, Goland \& Reissner (1944) introduce the correction factor k, and hence, the bending moment at the edges of the bonded assembly is expressed again by the following:

$M_{0}=k \frac{P t}{2}$

The factor $k$ in expression (10) is constantly smaller than 1.

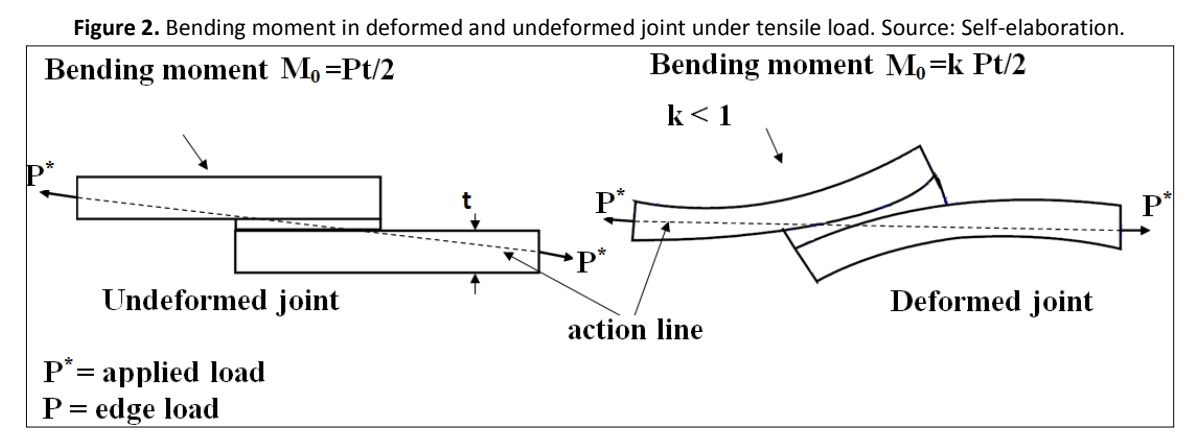

Given the changes in stiffness along the bonded assembly Goland \& Reissner(1944) divided their analysis on the joint in three plates: the two members and the overlap region (Figure 2). Equality between two expressions (4) and (10) can be written as follows:

$M_{0}=D \cdot\left[\frac{d^{2} w}{d x^{2}}\right]_{\text {atedge }}=k \frac{P t}{2}=\frac{1}{1+2 \sqrt{2} \tanh \frac{\lambda c}{2 \sqrt{2}}} \frac{P t}{2}$

With k, the correction factor of Goland and Reissner's bending moment is computed by the following:

$k=\frac{1}{1+2 \sqrt{2} \tanh \frac{\lambda c}{2 \sqrt{2}}}$

Where

$\lambda=\sqrt{12\left(1-v^{2}\right)} \frac{\sqrt{P / t E}}{t}=\sqrt{\frac{P}{D}}$

Where $E, t, v$ are adherend properties, and $c$ measures half the overlap length. 
Derivation of these equations is based on the following assumptions:

- The joint is symmetrical (identical adherends).

- Joint width is large compared with adherend thickness.

- Adhesive thickness is neglected.

- Angle $\alpha$ of the line of action is negligible in calculation of edge tension.

Shearing force $Q_{0}$ at the edge of the joint takes the form as follows:

$$
Q_{0}=-D\left[\frac{d^{3} w}{d x^{3}}\right]_{\text {at edge }}=k \frac{P t}{2} \sqrt{\frac{P}{D}}
$$

Shearing force in the overlap zone is determined by the equilibrium of the relative moment (Figure 3).

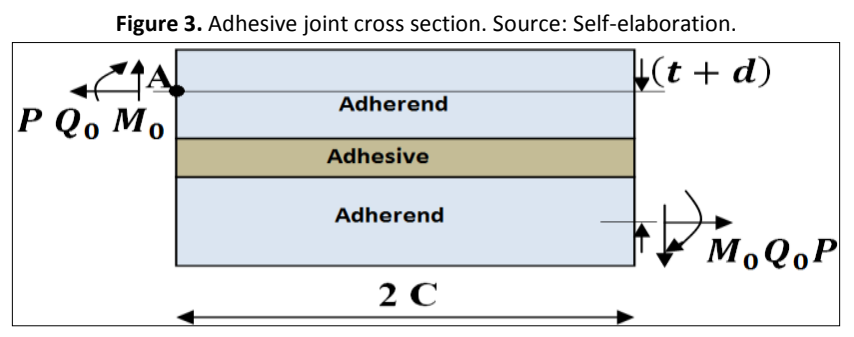

$Q_{\text {equilirum }}=\frac{(t+d) P-2 M_{0}}{2 c}$

Shear stress is given by the ratio between the shear force and cross-section. By solving the second-order differential equation, Goland \& Reissner(1944) led to the general expression for the shear stress.

$\tau(m)=\left[\frac{\beta \cdot c}{t} \cdot(1+3 \cdot k) \cdot \frac{\cosh \left[c \cdot \frac{\beta}{t} \cdot m\right]}{\sinh \left[\frac{\beta \cdot c}{t}\right]}+3 \cdot(1-k)\right] \cdot p \cdot \frac{t}{\beta \cdot c}$

$\beta=\sqrt{8 \cdot \frac{\text { Ga.t }}{E \cdot d}}$

Combination between study of (Cheuk \& Tong, 2002) and approach of (Goland \& Reissner, 1944)

According to Cheuk \& Tong(2002), bending moment MA can be possibly expressed in the presence of the crack with expression (7), but the existence of crack length significantly redistributes stresses in the adhesive layer and thus changes stress resultants in both adherends.

A lot of work has been conducted to understand and predict failure behavior of adhesive-bonded single lap joints. Based on existing research, the two important studies in this case are as follows:

Failure load increases by increasing crack length results, as predicted by Cheuk \& Tong(2002).

k factor decreases by increasing the applied load results, as predicted by Goland \& Reissne(1944)and Hart-Smith (1973).

From the two important studies, we can conclude that crack length increases as $\mathrm{k}$ factor decreases.

From expression (7), we can extract factor k:

$\mathrm{k}=\frac{\left(\frac{2 \cdot \mathrm{M}_{\mathrm{A}}}{\mathrm{P} \cdot \mathrm{t}}+\cosh \left(\mu_{2} \mathrm{x}_{\mathrm{A}}\right)\right)}{\left(1+\left(\frac{\mu_{1} \cdot \tanh \left(\mu_{2} \cdot \mathrm{x}_{\mathrm{A}}\right)}{\left(\mu_{2} \cdot \tanh \left(\mu_{2} \cdot \mathrm{l}\right)\right)}\right)\right)}$ 
Therefore, for calculation of shear stress at the adhesive layer in the presence of crack, we can use the expression (16) of Goland \& Reissner (1944). To visualize crack length effect on the values of shear stresses at the free edge of singlelap shear joint, we focused only on the crack length $x_{A}$ in the expression (17). Table 1 shows the shear stress in the adhesive layer of single-lap shear joints.

Table 1. Shear stress at free edge of overlap with k factor. Source: Self-elaboration.

\begin{tabular}{ccc}
$\begin{array}{c}\text { Half crack } \\
\text { length } X_{A}(\mathrm{~mm})\end{array}$ & $\begin{array}{c}\text { Shear stress at free edge } \\
\boldsymbol{\tau}_{\max }(\mathrm{MPa})\end{array}$ \\
\hline 0 & 0.3060 & 48.7997 \\
1 & 0.2718 & 46.4079 \\
2 & 0.2464 & 44.6336 \\
3 & 0.2275 & 43.3085 \\
4 & 0.2134 & 42.3215 \\
5 & 0.2030 & 41.5962 \\
\hline
\end{tabular}

This theory is based on differential equations for stresses of adhesive:

- Mechanical properties of adherends same as the T300/934 ASTM from (ASTM, 1994)

- Young's modulus E= 57226Mpa

- In plane Poisson ratio $=0.05$

- Out of plane Poisson ratio $=0.28$

- Mechanical properties of FM300K film adhesive ASTM (ASTM, 1994)

- Nominal bondline thickness $0.16 \mathrm{~mm}$

- Young modulus Ea=2400Mpa

- $\quad$ Poisson ratio $=0.32$

Table 2. Parameters of the geometric adhesive-bonded assembly. Source: Self-elaboration.

\begin{tabular}{lc} 
Geometrical parameters & Values $(\mathrm{mm})$ \\
\hline $\mathrm{c}:$ half-length covering & 25 \\
$\mathrm{~b}:$ width of the joint & 25.4 \\
$\mathrm{t}:$ thickness of adherends & 1.72 \\
$\mathrm{~d}:$ Adhesive thickness & 0.16 \\
\hline
\end{tabular}

\section{Effect of crack length on adhesive shear stress}

The shear stress along the bondline (adhesive mid-layer) is calculated and plotted against the overlap length for singlelap shear joint models with different crack lengths. Figure 4 shows shear stress distribution in the adhesive layer. We evaluated the shear stress at the edge in terms of gradual increase in crack length of $0-4 \mathrm{~mm}$. From this figure, this stress visibly decreases as a function of crack length because the crack absorbs some of the energy dissipated to both edges. Distributions of shear stress for different crack lengths $X_{A}=2 \mathrm{~mm}$ and $X_{A}=4 \mathrm{~mm}$ show the same distribution as the model without crack-only difference for the maximum shear stress at the end of free edge of the overlap part of singlelap shear joint.

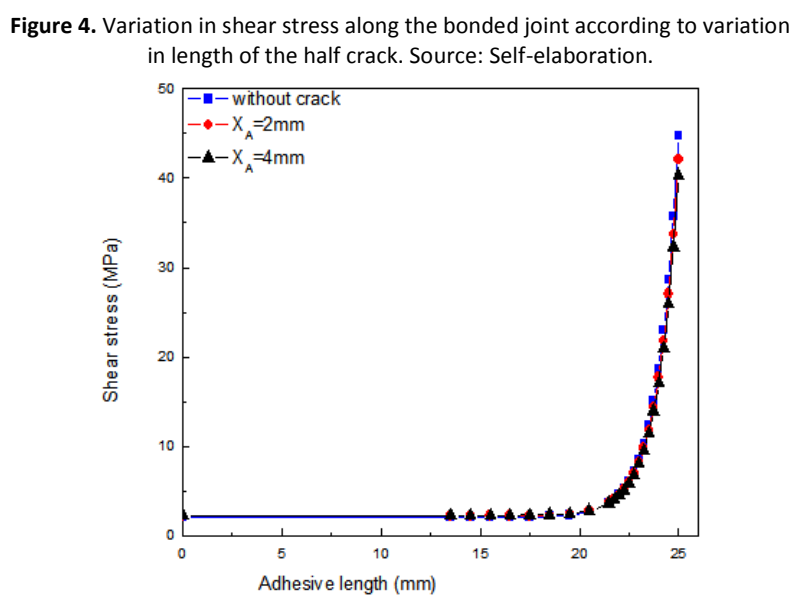




\section{Effect of crack position}

To evaluate the shear stress along the adhesive area, we varied the crack location from $0.215 \mathrm{~mm}$ to $1.075 \mathrm{~mm}$ of the bonded joint (Figure 5). As shown in Figure 5, the three curves follow the same pace, with the exception of a remarkable difference on the edge of the bonded joint. The presence of crack generates a small perturbation of stresses in the adhesive layer, and this perturbation or stress concentration decreases or disappears when the distance between the crack position and adhesive layer increases.

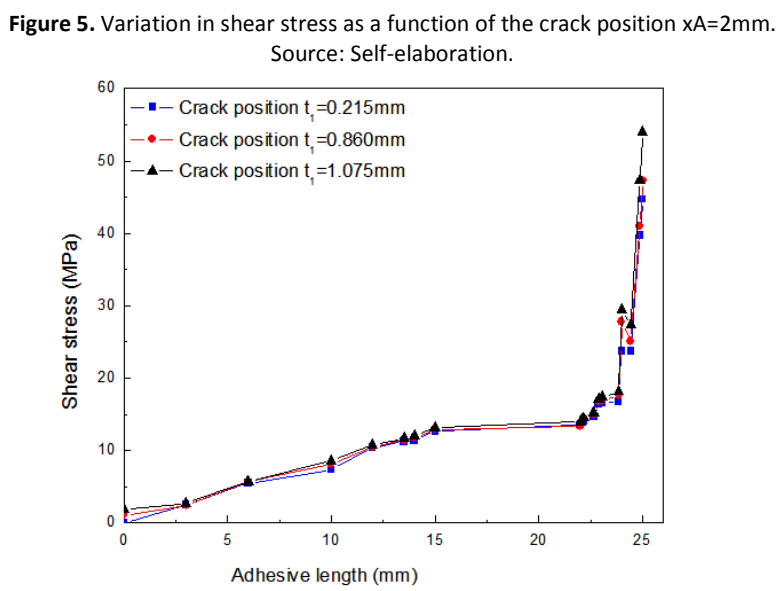

\section{Correlation between analytic and numerical results}

A good agreement exists between analytical and numerical results, as shown in Table 3. Maximum shear stress (at free edge) of adhesive layer care presented with different crack length when crack length increases from $2 \mathrm{~mm}$ to $10 \mathrm{~mm}$. Maximum shear stress predicted by FEA and analytic model decreases, and a small difference is observed between both models, as shown in Table 3.

Table 3. Comparison of maximum shear stress [MPa] between analytic and FEA results (Applied load: $410.22 \mathrm{~N} / \mathrm{mm}$ ). Source: Self-elaboration.

\begin{tabular}{lcccc}
$\begin{array}{l}\text { Crack length } \\
(\mathrm{mm})\end{array}$ & $\begin{array}{c}\text { Analytical model } \\
\boldsymbol{\tau}_{\max }\end{array}$ & $\begin{array}{c}\text { FEA Model } \\
\boldsymbol{\tau}_{\max }\end{array}$ & $\begin{array}{c}\text { Absolute relative } \\
\text { difference (\%) }\end{array}$ & K factor \\
\hline No crack & 74.6336 & 71.692 & 3.94 & 0.6757 \\
2 & 69.4567 & 68.561 & 1.29 & 0.6016 \\
4 & 65.4372 & 64.675 & 1.16 & 0.5441 \\
6 & 62.2691 & 62.450 & 0.29 & 0.4988 \\
8 & 59.7458 & 60.583 & 1.40 & 0.4627 \\
10 & 57.7237 & 58.083 & 0.62 & 0.4337 \\
\hline
\end{tabular}

An analytic study was carried out to investigate and validate results through FEA of the evolution of stresses in a bonded joint at interface and free edge with a crack. The analytic model was proposed for determination of bending moment in the cracked zone. The balance of this moment has been transferred to the interface to calculate shear stress along the adhesive layer of bonded joint. From the present results, the following conclusions are drawn:

- The presence of cracks significantly affects shear stress distribution in the adhesive layer.

- The presence of distant cracks exerts no effect on the distribution of shear stresses in the adhesive.

- Compared results showed good agreement between maximum shear stress of the cracked section calculated by FEA (ANSYS) and those of the analytic model at the free edge of adhesive layer.

This study presented an investigation of the crack effect and mechanic behavior on a composite-repaired structure, which is very important in preparation of a desirable material composite for repairing damaged structures. 
Adams, Robert D. (1989). Strength predictions for lap joints, especially with composite adherends. A review. The Journal of Adhesion, 30(1-4), 219242.

ASTM, D. (1994). 5528-94a, Standard test method for Mode I interlaminar fracture toughness of unidirectional fiber-reinforced polymer matrix composites. Annual book of ASTM standards, 15.

Cheuk, PT, \& Tong, Liyong. (2002). Failure of adhesive bonded composite lap shear joints with embedded precrack. Composites Science and Technology, 62(7), 1079-1095.

Erdogan, F, \& Ratwani, M. (1971). Stress distribution in bonded joints. Journal of Composite Materials, 5(3), 378-393.

Goland, Ma, \& Reissner, E. (1944). The stresses in cemented joints. Journal of applied mechanics, 11(1), A17-A27.

Hart-Smith, Leonard John. (1973). Adhesive-bonded single-lap joints: National Aeronautics and Space Administration.

Hart-Smith, L. (1973). Adhesive-bonded double-lap joints technical report, NASA CR-112235. Hampton, VA: NASA Langley Research Center.

Hart-Smith, L. (1985). Designing to minimize peel stresses in adhesive-bonded joints. Delamination and debonding of materials: ASTM International.

Hutchinson, John W, \& Suo, Zhigang. (1991). Mixed mode cracking in layered materials. Advances in applied mechanics, $29,63-191$.

Kairouz, KC, \& Matthews, FL. (1993). Strength and failure modes of bonded single lap joints between cross-ply adherends. Composites, 24(6), 475484.

Rybicki, Edmund F, \& Kanninen, Melvin F. (1977). A finite element calculation of stress intensity factors by a modified crack closure integral. Engineering Fracture Mechanics, 9(4), 931-938.

Tong, L. (1998). Failure of adhesive-bonded composite single lap joints with embedded cracks. AIAA journal, 36(3), 448-456.

Tong, Liyong, \& Steven, Grant P. (1999). Analysis and design of structural bonded joints. Univ. of Sydney, New South Wales (AU). 